\title{
ELECTROCHEMISTRY OF INORGANIC NANOCRYSTALLINE ELECTRODE MATERIALS FOR LITHIUM BATTERIES
}

\author{
C. W. KWON ${ }^{\mathrm{a}}$, S. J. HWANG ${ }^{\mathrm{a}}$, M. H. DELVILLE ${ }^{\mathrm{a}}$, C. LABRUGÈRE ${ }^{\mathrm{a}}$, \\ A. VADIVEL MURUGAN ${ }^{\mathrm{b}}$, B. B. KALE ${ }^{\mathrm{b}}, \mathrm{K}$. VIJAYAMOHANAN $^{\mathrm{c}}$ and G. CAMPET ${ }^{\mathrm{a}, *}$ \\ anstitut de Chimie de la Matière Condensée de Bordeaux du CNRS, \\ 87 Avenue du Dr. A. Schweitzer, 33608 Pessac Cedex, France; \\ ${ }^{\mathrm{b}}$ Center for Materials for Electronics Technology, Ministry of Information Technology, \\ Government of India, Panchwati, Pashan Road, Pune 411 008, India; \\ ${ }^{\mathrm{c}}$ National Chemical Laboratory, CSIR, Pashan Road, Pune 411 008, India
}

(Received 28 June 2002; In final form 3 July 2002)

\begin{abstract}
Traditional electrode materials are based on the redox potential difference of the electrode in the course of intercalation/deintercalation reactions. They are generally well-crystalline host compounds either with layered structure such as $\mathrm{LiCoO}_{2}$ and $\mathrm{LiNiO}_{2}$, or with tunnel structure like $\mathrm{LiMn}_{2} \mathrm{O}_{4}$. Nanocrystalline materials are, however, being re-evaluated recently as 'nanoscience' advances. The electrochemistry of this kind of materials is much different from that of traditional crystalline ones because of their significant 'surface effects'. In connection with that, the nanocrystalline cathode materials are reported to have an enhanced electrochemical activity when the first significative electrochemical step is insertion of $\mathrm{Li}$ ions (discharge process). The "electrochemical grafting" concept will be given as a plausible explanation. As illustrative examples, electrochemical behaviors of nanocrystalline manganese oxydes are presented.
\end{abstract}

Keywords: Nanocrystalline cathode materials; Manganese oxydes; Lithium batteries

\section{INTRODUCTION}

The birth of 'nano-technology' is one of the most fruitful scientific progress in the last 20th century. This contemporary advance endows mankind to handle and interpret the structure of matters based on molecular or cluster levels. Exploration below a critical size found many curious phenomena such as quantum size effects, superparamagnetism and so on. Insofar as electrochemistry is concerned, it is found that the electrochemical behaviors of nanoparticles are much different from those of microcrystalline ones because they have significant 'surface effects' [1]. Related to that, some of us have shown that the control of crystallite size was a key factor determining the specific capacity and the cycling efficiency of the electrodes, and important observations were deduced [2,3]; the main lines are reported below for sake of clarity: 'nanocrystalline cathode materials will have an enhanced electrochemical

\footnotetext{
* Corresponding author. E-mail: campet@icmcb.u-bordeaux.fr
} 
activity, compared with their microcrystalline homologue, when the first significative electrochemical step is an insertion of $\mathrm{Li}^{+}$ions (corresponding to a discharge of the $\mathrm{Li}$ battery). This insertion will begin with an electrochemical grafting of $\mathrm{Li}^{+}$ions, promoted by structural defects at/near the nanocrystallite surface'. This concept is depicted on Figure 1 showing a schematic band model for this grafting process. The nanocrystalline materials have many subband-gap states between the conduction band and valence band originating from surface defects (distorsion of coordination polyhedra, dangling bonds etc.). In the figure, the metal subband represents deep subband gap energy states arising from such structural defects. The first electrochemical $\mathrm{Li}^{+}$insertion process (process 1 in Fig. 1) fills these localized subband-gap states, and consequently gives a more smooth discharge curve compared to the well-crystalline homologue. It means a regular and smooth change of Fermi-energy in the electrode without undergoing any significant structural change. Therefore, nanocrystalline materials can endure better for structural phase transitions. We named the electrochemical step 1 the electrochemical grafting. This process can be reversible, depending upon the bond strength of the grafted lithiums. Moreover, as the cationic subband-gap states are progresively filled during the electrochemical grafting, the grain surface can be modified in such a way that the following electrochemical processes 2 and $2^{\prime}$, corresponding to electron injection in CB (Fig. 1), have enhanced reversibility. In these regards, nanocrystalline materials can be more efficient than their well-crystalline homologues. Let us quote that similar event can also occur if another 'surface constraint' is applied such as the physisorbtion with a conductive polymer [3,4]. In the present case, let us recall, for sake of clarity, that the nanocrystalline cathode materials can be advantageously considered if the first significative electrochemical step is a discharge of the Li battery, corresponding to an insertion of $\mathrm{Li}^{+}$ ions in the nanocrystalline cathode material starting, thereby, by the electrochemical grafting, because the cationic subband-gap states have the lowest energy. On account of that, the reverse trend would logically occur during the following charge of the Li battery, i.e. the electrochemical de-grafting would be the last step. We would like to believe that this model, which highlights the surface effects, can deliver a useful insight to develop more effective electrodes. It foresees when it is preferable to consider nanocrystalline electrodes rather

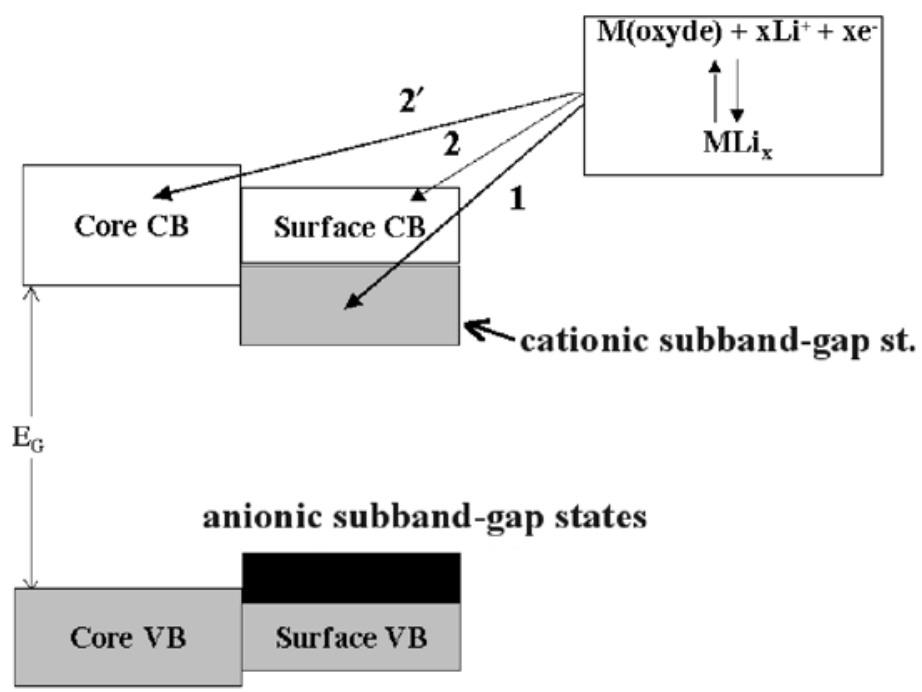

FIGURE 1 A schematic band model for the electrochemical grafting process. 
than their microcrystalline homologues. This is important for industrial stanpoint, because the nanocrystalline materials can be advantageously prepared at low temperatures, using thereby low-cost synthetic processes.

In this report, a special highlight will be made on the surface effects of electrode materials based on nanocristalline manganese oxides.

\section{NANOCRYSTALLINE ALKALI-METAL MANGANESE OXYIODIDE}

As mentioned above, the capacity fading problem originating from the phase transitions is regarded to be more or less inevitable for the well-crystalline lithium manganese oxides. The above reported speculations give an impetus to develop nanocrystalline phases as alternative cathode materials, since this type of compounds would not suffer from the irreversible phase changes and endure better for the repeated Li insertion-deinsertion processes.

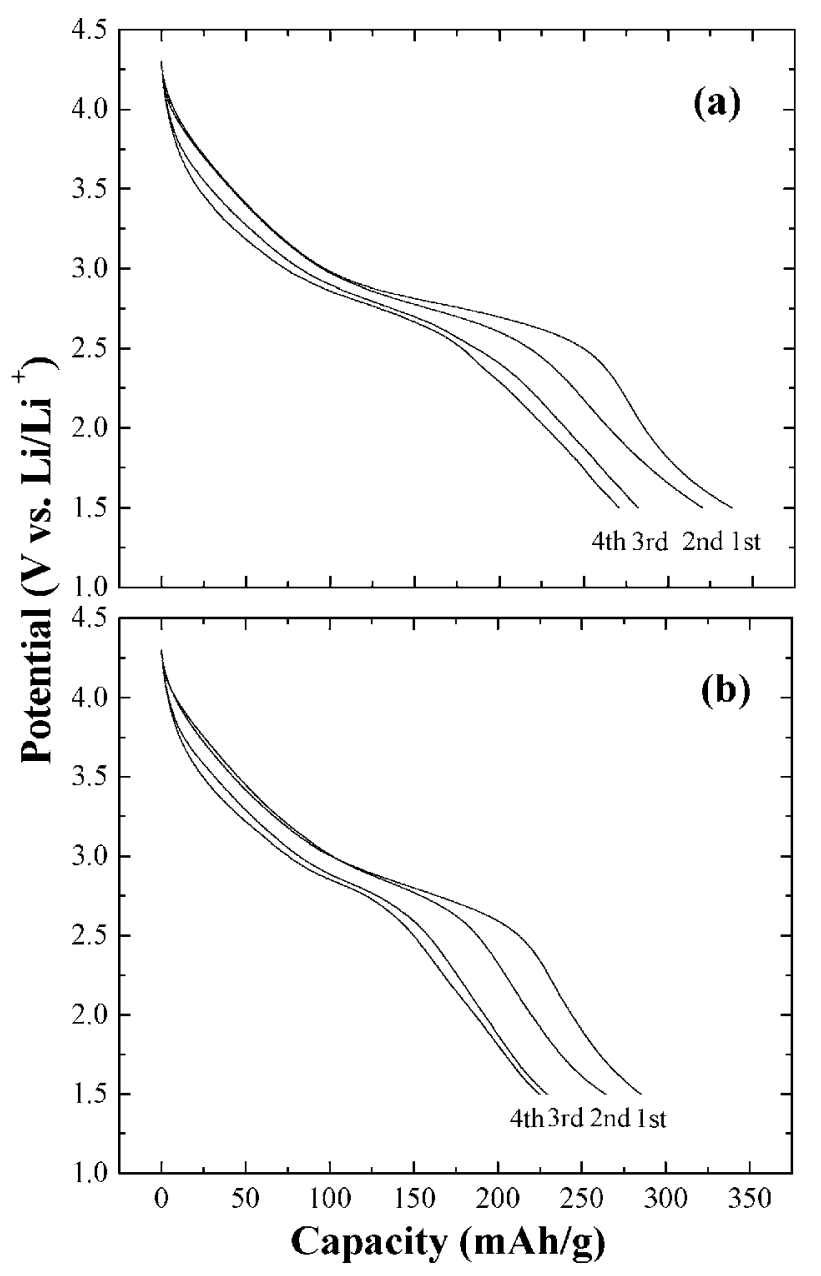

FIGURE 2 Discharge potential $v s$. capacity profiles of the $\mathrm{A}-\mathrm{Li}-\mathrm{Mn}-\mathrm{O}-\mathrm{I}$ compounds with $\mathrm{A}=(\mathrm{a}) \mathrm{K}$ or (b) $\mathrm{Na}$ between $1.5 \sim 4.3 \mathrm{~V}$ vs. Li at a constant current density of a $0.2 \mathrm{~mA} / \mathrm{cm}^{2}$ for $20 \mathrm{mg}$ of active mass. 
Amorphous manganese oxides are normally prepared by reduction and precipitation of permangates such as $\mathrm{NaMnO}_{4}$ or $\mathrm{KMnO}_{4}$ [5]. Currently, we have synthesized alkali metal-based lithium manganese oxyiodide by reaction the aqueous solution of $\mathrm{KMnO}_{4}$ (or $\mathrm{NaMnO}_{4}$ ) with 1.5 equivalent $\mathrm{LiI}$ at room temperature [6]. Chemical analysis gave the compositions of $\mathrm{Li}_{0.54} \mathrm{~K}_{0.31} \mathrm{MnO} \sim 2.5 \mathrm{I}_{0.10}$ (or $\mathrm{Li}_{0.52} \mathrm{Na}_{0.62} \mathrm{MnO} \sim 2.5 \mathrm{I}_{0.07}$ ). X-ray diffraction gave evidence of their nanocrystalline character. The local crystal structure around manganese in these compounds has been determined by performing the combinative micro-Raman and X-ray absorption spectroscopy [6]. These analysis reveal that the structural distortion caused by lithiation process is not marked, in agreement with the above quoted observations. Moreover, the crystal structure of K-based nanocrystal is more tolerable for $\mathrm{Li}$ insertion than the Na-based one. In this context, the greatest discharge capacity observed for the potassium-based nanocrystalline material (Fig. 2) is not only attributable to an efficient electrochemical grafting process (step 1 in Fig. 1), but also to the pillaring effect of larger potassium ions, providing an expanded interlayer space available for

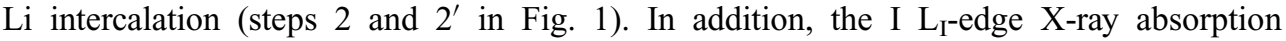
near edge structure results [6] made it clear that the iodine is stabilized as iodate species on the grain boundary or surface of the nanocrystalline manganese oxyiodide, which helps to maintain the nanocrystalline nature of the present materials before and after Li insertion.

\section{NANOCRYSTALLINE OXIDE $\mathrm{LiMn}_{2} \mathrm{O}_{4}$}

It must be recalled that the early spinel materials possessed a satisfactory theoretical specific capacity [7]. However, studies on its utilization have mainly focused on the $4 \mathrm{~V}$ domain, because the capacity fades severely in the $3 \mathrm{~V}$ range due to the occurrence of Jahn-Teller distortion when the average valence of $\mathrm{Mn}$ falls below +3.5 . The use of nanocrystalline material to overcome this shortcoming was first attempted by Bruce's group. In this prospect, a solution method has been used which advantageously involves a synthetic procedure carried out in air from manganese acetate and lithium carbonate [8]. Our objective here which is related to the above quoted electrochemical model is to compare nano and microcrystalline $\mathrm{LiMn}_{2} \mathrm{O}_{4}$ electrodes prepared respectively at 250 and $700^{\circ} \mathrm{C}$. The oxydes were synthesized either by using Bruce's procedure or by using an original polymeric route, that we have recently patented and which would be more adapted to large scale production [9]. In that case, homogeneous starting materials were obtained from an aqueous $\mathrm{HNO}_{3}(1 \mathrm{~N})$

TABLE I Relative Proportion of $\mathrm{Mn}^{\mathrm{IV}+} / \mathrm{Mn}^{\mathrm{III}+}$, Average Particle Size, Coordination Number $(\mathrm{CN})$, and Bond Distance of $\mathrm{LiMn}_{2} \mathrm{O}_{4}$ Prepared at $250^{\circ} \mathrm{C}$.

\begin{tabular}{lcc}
\hline Sintering temperature & $250{ }^{\circ} \mathrm{C}$ & $700{ }^{\circ} \mathrm{C}$ \\
$\mathrm{C}_{\mathrm{Mn}} \mathrm{III+}$ & $41.0 \%$ & $55.5 \%$ \\
$\mathrm{C}_{\mathrm{Mn}} \mathrm{IV}+$ & $59.0 \%$ & $44.5 \%$ \\
Average particle size & $\sim 5 \mathrm{~nm}$ & $\sim 100 \mathrm{~nm}$ \\
$(\mathrm{Mn}-\mathrm{O})$ & & \\
$\mathrm{CN}$ & 5.6 & 6.0 \\
$\mathrm{R}(\AA)$ & $1.90(4)$ & $1.91(5)$ \\
$(\mathrm{Mn}-\mathrm{Mn})$ & & \\
$\mathrm{CN}$ & 5.2 & 6.0 \\
$\mathrm{R}(\AA)$ & $2.88(9)$ & $2.89(5)$ \\
\hline
\end{tabular}


solution to which appropriate amounts of polyacrylamide (Paam), lithium carbonate and manganese (II) acetate tetrahydrate were added. First a gel is formed and a xerogel (hybrid polymer) is prepared after removal of the solvent. The controlled explosive oxydo-reduction under oxygen atmosphere of the hybrid polymer leads to fine powder of the spinel phase. Both procedures $[8,9]$ yield similar results. First, the comparative study between SEM, TEM, XPS and XAS, established that a lowering of synthetic temperature gives rise to an increase of structural disorder and of the average oxidation state of manganese (Table I). Moreover, we found that these phenomena were more significant at the surface than in the bulk $[2,3]$. Such results suggest that the lowering of synthetic temperature can strongly modify the chemical environment of ions and their oxidation state at/near the grain surface. That would change the electronic properties with the formation of surface- $\mathrm{Mn}^{4+}: 3 \mathrm{~d}_{\mathrm{eg}}^{0}$ states, stabilized against bulk- $\mathrm{Mn}^{4+}: 3 \mathrm{~d}_{\mathrm{eg}}^{0}$ states, according to the schematic band model of Figure 1 . It would imply that the chemical bonding nature of the first electrochemically inserted lithiums are different between nano and microcrystalline samples, because the reduction of $\mathrm{Mn}^{4+}$ is involved in the electrochemical process, and for the nanocrystalline sample it should be the
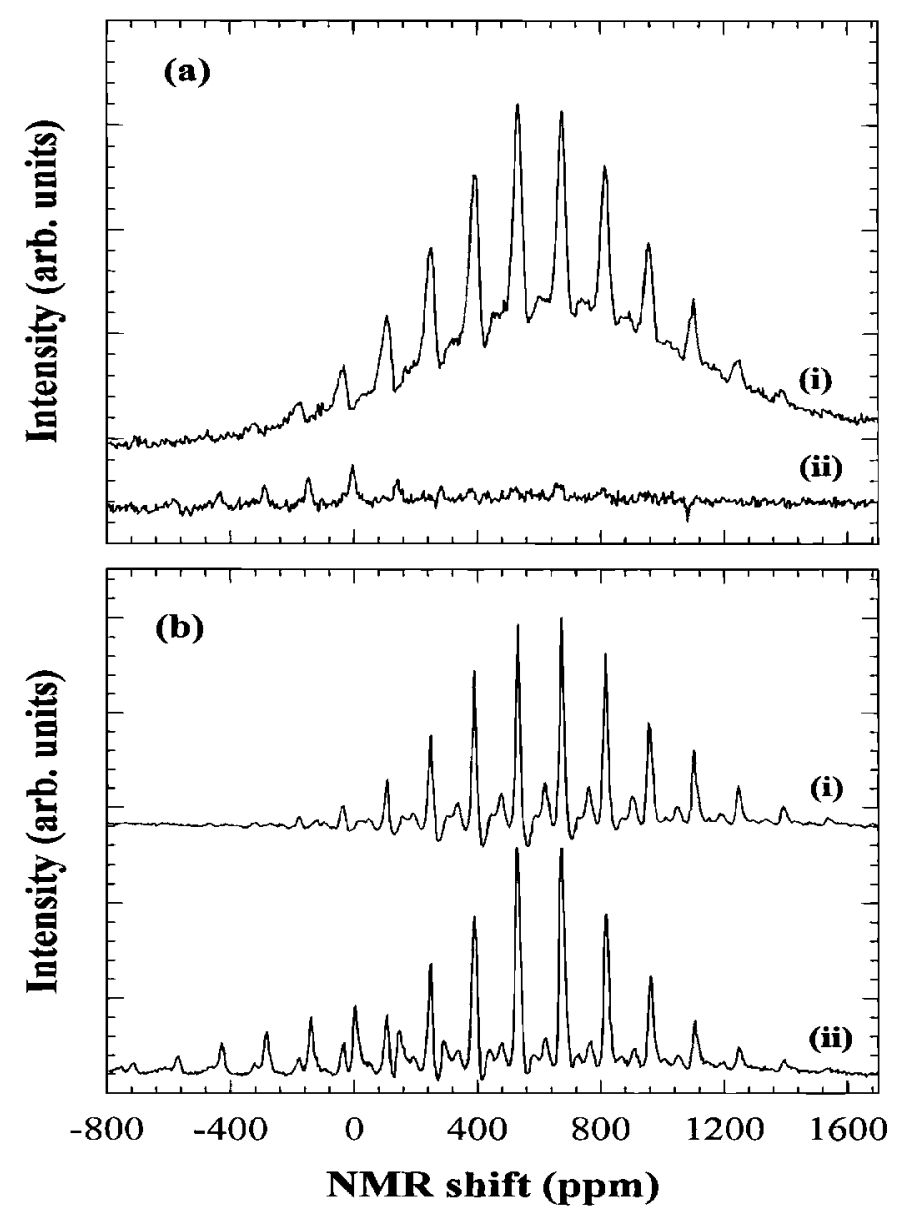

FIGURE 3 A comparison of ${ }^{7} \mathrm{Li}$ MAS NMR spectra (i) before and (ii) after the insertion of $0.2 \mathrm{~mol} \mathrm{Li}^{+}$for (a) the nanocrystalline $250^{\circ} \mathrm{C}$ sample and (b) the microcrystalline $700^{\circ} \mathrm{C}$ sample. 
above mentioned surface- $\mathrm{Mn}^{4+}$ that are firstly reduced to $\mathrm{Mn}^{3+}$ so that the 'electrochemical grafting' of $\mathrm{Li}^{+}$would occur at the viscinity of these reduced surface manganese in order to maintain the electroneutrality. Related to that, for the purpose of examining the evolution of the chemical bonding nature of the first inserted lithium, ${ }^{7}$ Li MAS NMR studies have been performed for both nanocrystalline and microcrystalline spinels before and after the insertion of only $0.2 \mathrm{~mol}$ of $\mathrm{Li}^{+}$(Fig. 3). While the insertion does not induce any remarkable spectral change for the well-crystalline $\mathrm{LiMn}_{2} \mathrm{O}_{4}$ as it could be reasonably expected [7], it leads to a dramatic suppression of the NMR signal for the nanocrystalline one. It would indicate that the 'electrochemical grafting' process of $\mathrm{Li}^{+}$ions, described above, modifies not only the surface as expected, but also the core-electronic structure of the nanograins. In agreement with the model, only the nanocrystalline sample shows good cyclability in the $3 \mathrm{~V}$ region and a smooth change of Fermi-energy at the beginning of the insertion (Fig. 4).

Therefore, the grafting and following insertion processes are reversible for the nanocrystalline $\mathrm{LiMn}_{2} \mathrm{O}_{4}$. These assertions have been supported by Goodenough's group who showed that a simple ball-milling of well-crystalline spinel powders generates nanograins and intraparticular strain, and increase manganese oxidation state, leading to an enhanced cyclability
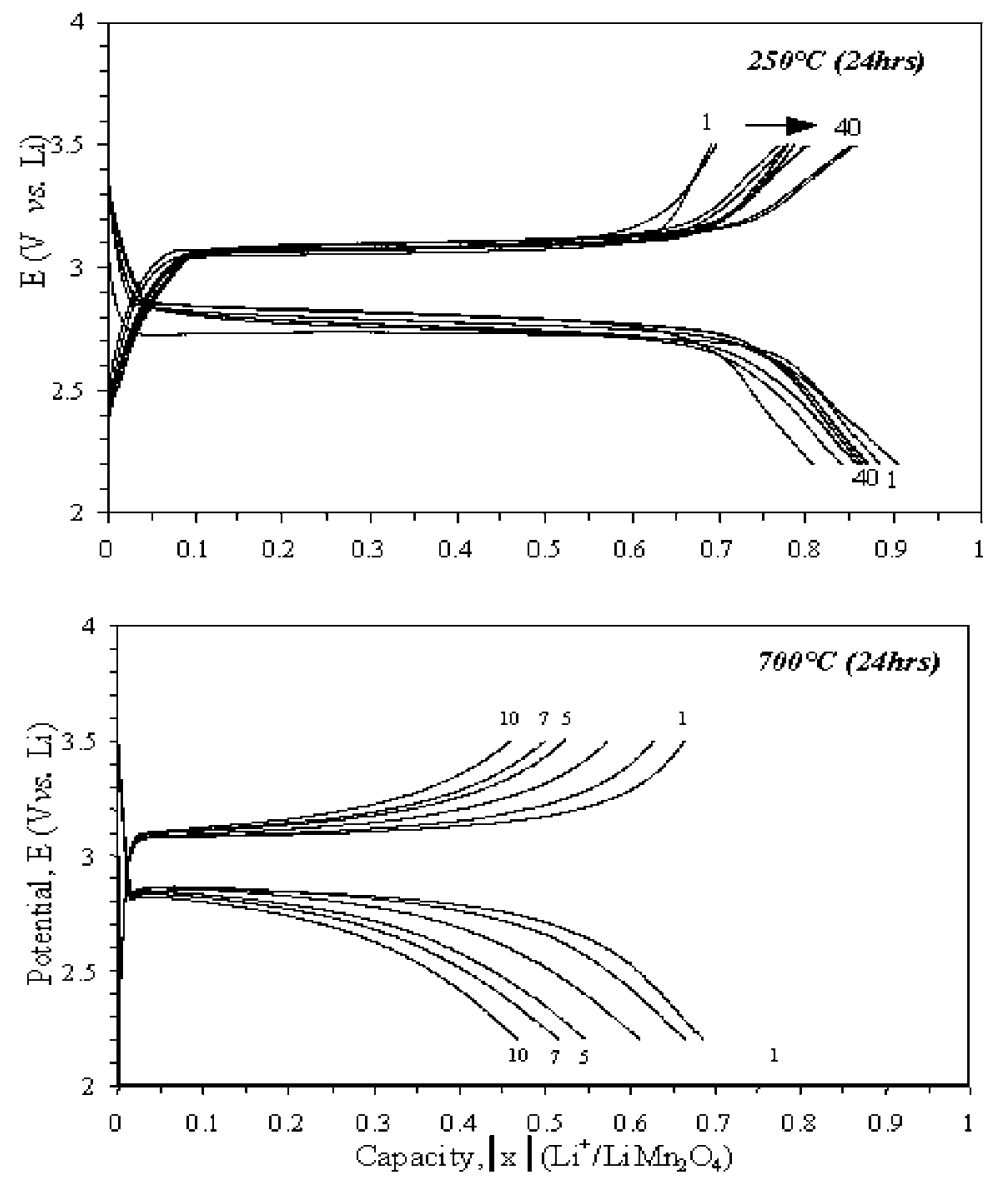

FIGURE 4 Charge-discharge profiles, in $3 \mathrm{~V}$ domain, for nano and microcrystalline $\mathrm{LiMn}_{2} \mathrm{O}_{4}$ prepared respectively at $250{ }^{\circ} \mathrm{C}$ and $700^{\circ} \mathrm{C}$. 
in the $3 \mathrm{~V}$ domain [10]. Such results can indeed be understood in the same context of the electrochemical grafting.

\section{CONCLUSION}

The electrochemistry of nanocrystalline electrode materials differs from that of traditional well-crystalline ones due to their significant surface effects. The electrochemical grafting concept would be advantageously served for a qualitative comprehension of the "nanophenomena' observed for nanocrystalline $\mathrm{LiMn}_{2} \mathrm{O}_{4}$ and potassium manganese oxyiodide.

\section{References}

[1] Campet, G., Wen, S. J., Han, S. D., Shastry, M. C. R., Portier, J., Guizard, C. and Cot, L. (1993). Mater. Sci. Eng., B18, 201-208, and references therein.

[2] Treuil, N., Labrugère, C., Menetrier, M., Portier, J. and Campet, G. (1999). J. Phys. Chem. B, 103, 2100-2106.

[3] Kwon, C. W., Mornet, S., Delville, M. H., Barlieri, C., Vadivel Murugan, A., Kale, B. B., Vijayamohanan, K. and Campet, G. (2002). Seventh International Symposium on Advances in Electrochemical Science and Technology (ISAEST-VII), Chennai, India, Nov 27-29 2002.

[4] Kwon, C. W. (2002). PhD thesis, Univ. Bordeaux-1, France, and references therein.

[5] Xu, J. J., Kinser, J. B., Owens, B. B. and Smyrl, W. H. (1998). Electrochem. Solid State Lett., 1, 1-3.

[6] Hwang, S. J. (2001). PhD thesis, Univ. Bordeaux-1, France.

[7] Goodenough, J. B., Thackeray, M. M., David, W. I. F. and Bruce, P. G. (1984). Revue de Chimie Minérale, 21, 435-442, see for instance.

[8] Huang, H. and Bruce, P. G. (1994). J. Electrochem. Soc., 141, 76-77.

[9] Treuil, N., Portier, J., Campet, G., Ledran, J. and Frison, J. C. (1999). Europ. patent EP0837036.

[10] Kang, S. H., Goodenough, J. B. and Rabenberg, L. K. (2001). Chem. Mater., 13, 1758-1764. 

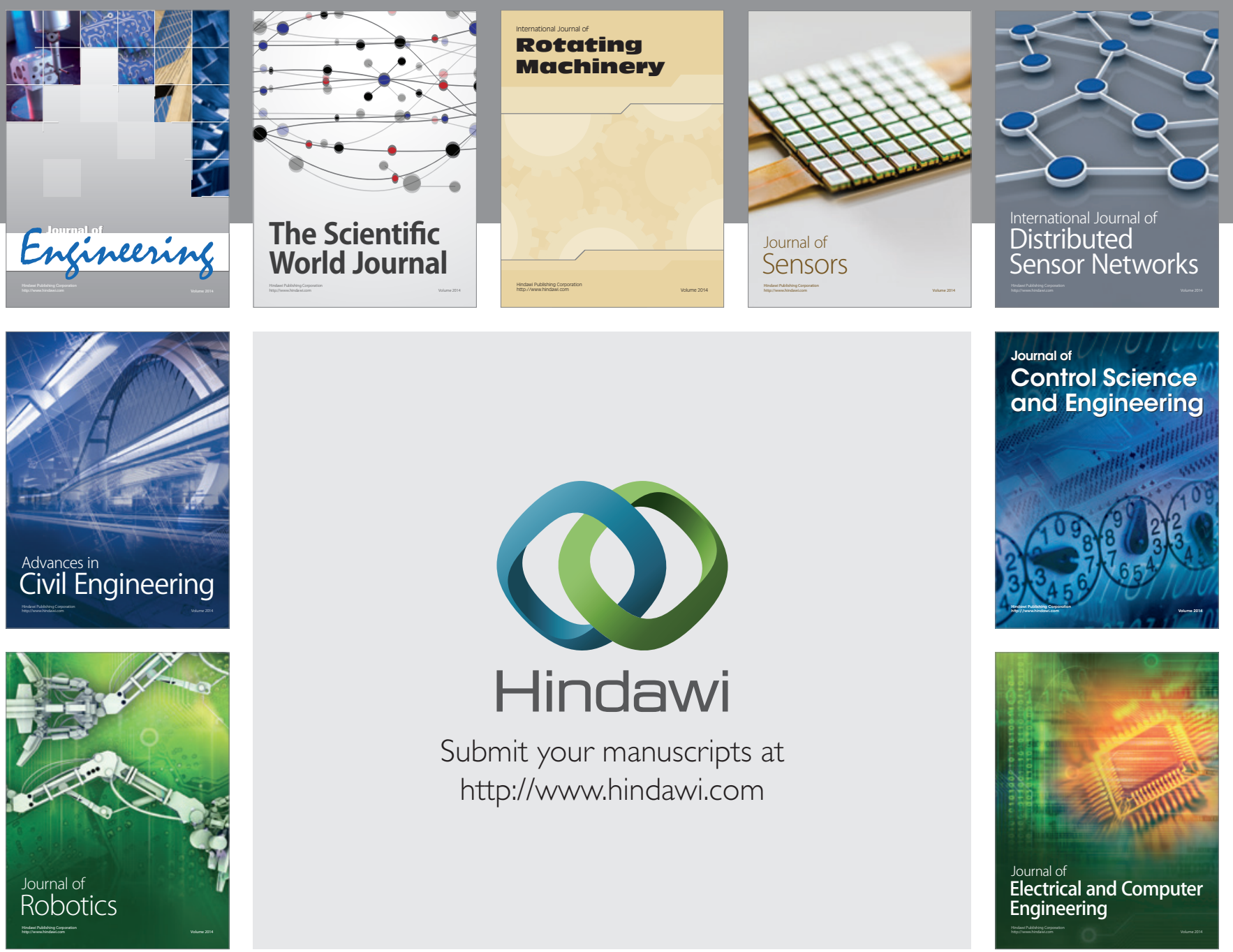

Submit your manuscripts at

http://www.hindawi.com
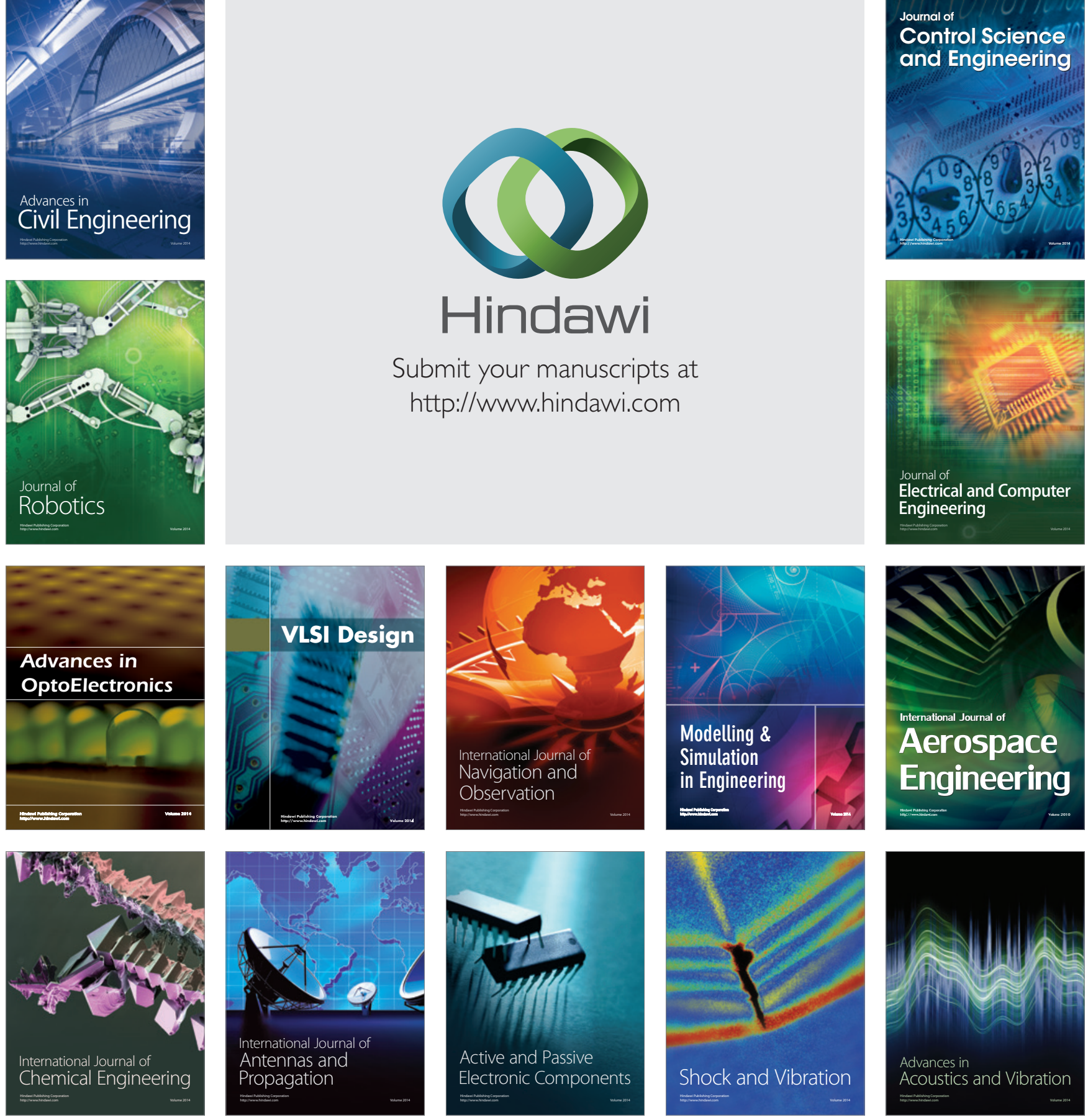